\title{
The Relationship between Intrinsic Motivation and Academic Achievement of Male and Female Students at University Level in Pakistan: A Case Study
}

\author{
${ }^{*}$ Sadaf Tariq ${ }^{1}$, Shafqat Hussain ${ }^{2}$, Sumaera Mahmood ${ }^{1}$, Sarwat Mubeen ${ }^{1}$ \\ ${ }^{1}$ Foundation University, Pakistan \\ 2Education Department K.P.K, Pakistan \\ *pink.star1987@yahoo.com
}

\begin{abstract}
ASTRACT: Psychologists and educators believe motivation as a significant factor that has an effect on student learning and accomplishment. It is a general argument that suitable motivational orientations make learning easy while unsuitable ones obstruct it. Intrinsic motivation is a kind of motivation that approach from individual factors within a person rather than merely from some outside motives. Intrinsic motivation shows learners commitment in learning for its personal interest. In Pakistan, perhaps little research has yet been done in this field. The study was conducted to find the relationship between intrinsic motivation and academic achievement of students at university level in province Punjab, Pakistan. The main objectives of study were, to finds out profiles of students with respect to intrinsic motivation and academic achievement, to find out difference among male and female students on intrinsic motivation and academic achievement. The population of the study comprised of 600 male and female students studying in universities of Punjab, Pakistan. The sample consisted of 300 male and 300 female students of universities selected through multistage sampling procedure. In order to measure intrinsic motivation of students, an adapted version of Harter's (1981) intrinsic motivation scale was used. Academic achievement of students was measured through their university results. The scores on each variable were calculated and summarized through mean and standard deviation scores. The significance of difference between mean scores of male and female and BA and B.Sc students on the study variables were calculated by t-test (two-tailed). The relationship between intrinsic motivation and academic achievement was computed by using Person ' $r$ '. The results of the study revealed no gender difference. Both male and female were found to be equal in intrinsic motivation and academic achievement.
\end{abstract}

Key words: Intrinsic Motivation, Academic Achievement, Punjab, Pakistan

\section{Introduction and Literature}

Motivation is a significant issue in teaching and education course. It not only set the activity but also concerned with the arousal of that activity. It is a psychological process that that give behavior purpose and direction. There are different theories of motivation such as behavioral, humanistic, cognitive, and social theory, which are explained differently but are important part of motivation. Two diverse types of motivation are Intrinsic and extrinsic motivations. It is found by the reviewed studies that intrinsic enthusiasm is lost in students when introduction of extrinsic motivation interjects. Self-determination theory refers intrinsic motivation as performing activity as it is innately motivating and extrinsic motivation indicates to performing activity for the reason that it show the way to distinguishable outcomes.

According to Ryan et al (2000), Motivation is an inside condition that stimulates, guides, and sustain goal oriented actions. Particularly, motivation is a process to gain knowledge according to the nature and interest of students who try to come across and get the future reimbursements from those educational behaviors that are significantly valuable and applicable. Motivation, as viewed from educational perspective, has been debated and studies theoretically since 1950's. It is described as an inclination and longing to connect in a set amount of work or activity for a certain reason. More over it is a process that is connected with arousing, directing and sustaining the behavior. Motivation has been a central discussion among psychologists due to its strong relation with the biological, cognitive and social regulation factors and its consequences on human behavior. Motivation is assign to represent our energetic actions that includes, desires, wants, goals, objectives and inspirations of being. It is the essential force for all our behaviors. Motivation to learn is vital aspect of motivation. It is based on obtaining achievements and attaining ambitions and goals of life. The desire to achieve effects the way person carry out an activity through which he desired to demonstrate capability (Harackiewicz, et.al 1997). Arif (2003) defined 
motivation as, an ultimately abstruse concept and motivating students a critical task of teaching. Motivation to learn is influenced by both environmental and personal factors. All the factors such as needs, goal, beliefs, attributions, expectations, reward and incentives effects motivation. How to put all this knowledge into creating a classroom environment that encourages motivation is the main issue. Teacher is the chief agent in creating this environment whose motivation itself is the key factor to inspire demotivated and uninterested students (Arif, 2003.p 163).

Motivation has been a central discussion among psychologists due to its strong relations with the biological, cognitive and social regulation factors and its consequences on human behavior .It is considered as a multidimensional phenomenon because people have various explanations for the engagement in an activity, the different levels of inclinations and the type of motivational orientation. In the motivational theory, two distinctive types of motivational orientations, intrinsic and extrinsic, have been emphasized. Intrinsic motivation is a genuine motivation that emerges from a personal inclination or incentive towards a specific task for the natural enjoyment aroused from involvement in the activity per se, while extrinsic motivation refers to an engagement in an activity to attain a specific goal or as an instrumental means to an end (Ryan et al, 2000). In the beginning when psychologists started paying attention towards motivation, White (1959) explained intrinsic motivation as a sort of reason to be expert in the task. People look for challenges to learn new abilities only for the enjoyment to be expert in the task and achievement. Intrinsic motivation is a motivational value of a sense of control. Man finds the exercise of control over their environment to be inherently motivating (Hunt, 1965. P. 22). Harter (1981) portrayed intrinsic motivation as inquisitiveness or an interesting activity that guide learners to search for the activities which seems difficult but wanted to master them with enjoyment. According to him intrinsic motivation have three mechanisms namely, challenge, interest and self-regulating mastery.

It was sustained that intrinsically motivated learners do not rely on teachers rather they were expected to prefer innovative and challenging tasks, they are inclined to learn new and complicated tasks, work out immense autonomy on learning. Other researchers like Hidi et al (2000) also support that in any learning activity student's interest and inquisitiveness is the major trait of intrinsic motivation. Importance of intrinsic motivation in any educational situation has showed by a great deal of research results. It is vital because it is related with improved interest, determination, perseverance and abilities to learn a task (Hidi, 2000). According to Krapp et al (1992) academic achievement and deep study, strategies are significantly related with intrinsic motivation. Students who are intrinsically motivated use deep study strategies and show higher academic achievement. It has proved by the previous study results that with regard to gender dissimilarities there had been contradictory results. The study conducted by Boggiano and Gallo (1991) and Boggiano et al (1992) showed that girls studying in elementary level were prejudiced by teacher feedback and were extrinsically motivated. While, Meece et al (1996) states that girls were found to be more intrinsically motivated. However, some of the studies reported no gender differences. Hagborg (1995) found that both male and female in high school show no dissimilarity in their tendency towards intrinsic motivation. The result of the study determines that academic achievement of both male and female students had positive relationship with intrinsic motivation. Rusillo and Arias that both genders do not vary in their ability towards intrinsic motivation also reported it. The above theory and research based discussion on the complex nature of motivation appears to revealed that intrinsic motivation indicates a higher level of motivation to learn which leads to superior academic performance. More over research on gender differences on these components of motivation is conflicting. These insights about the nature of motivation to learn need further probe in order to confirm the existing literature, especially in the context of Pakistan where research o the latest frontiers of knowledge on motivation is lacking. The study was therefore, designed to find out relationship between intrinsic motivation and academic achievement.

In Pakistan, a small number of studies have been found to be done in this field of research. There is need to conduct such studies to spread awareness among teachers and students, so that they will consider motivational factors while teaching and learning. It is also important for policy makers and administrators that while making policies and developing curriculum, such material should be included in course material which is according to needs and interest of pupils and which arouse curiosity in them for learning. Our system of education will definitely be improved if we have knowledge about these terms. The literature reviewed thus far on motivation indicates that motivation to learn is increased while basis of motivation is intrinsic relatively to extrinsic, the student is motivated to achieve success rather avoid failure, has high self-efficacy and low anxiety, attributes success and failure to controllable causes rather 
than uncontrollable causes, has some choice and freedom in what he/she does and believes that ability can be improved through effort.

Ormroid (1998) has derived a few general principles of motivation from the literature on motivation: When students have high self-efficacy and self-determination, they are said to be intrinsically motivated. Students with learning goals engage in those mental processes and behaviors that promote learning. Students are more likely to succeed at challenging classroom tasks if they are eager to do well and are not anxious about their performance. Students are more expected to achieve in the classroom when they characterize their achievements and failures to issues over which they think are improvable.

Although much research has already been carried out in the field of motivation through which importance of motivation for students can be demonstrated, still there is obvious need to conduct further research in educational surroundings (primary to university level) to understand complex nature of motivation. The research is significant, as it will provide guidelines to teachers, administrators and policy makers for inspiring students to struggle for learning. To find out profiles of students with respect to intrinsic motivation and academic achievement. To find out difference among male and female students on intrinsic motivation and academic achievement.

\section{Hypothesis}

- There is no significant difference between mean intrinsic motivation scores of male and female students at university level.

- There is no significant difference between mean academic achievement scores of male and female students at university level.

- There is no significant correlation between mean intrinsic motivation scores and academic achievement scores at university level.

\section{Methodology}

The population of the study consisted of university students, male and female in Punjab province (Pakistan). There are 36 districts in Punjab and total number of Degree colleges was 323 in which 171 were female and 152 were male colleges (Punjab University, 2011). From each university 100 students were chosen. In order to select the sample, two-stage cluster sampling technique was used because the population was too large and it was not possible to collect data from the whole population. In the first stage, from above colleges, 4 colleges, 2 male and 2 female were randomly selected. A sample of 600 students, 300 male and 300 female, was then, randomly selected from these colleges in the second stage as a sample of the study. The distribution of male and female in the sample was as under:-

\begin{tabular}{lllll}
\hline S.No & District & Male & Female & Total \\
\hline 1. & Gujranwala & 100 & 100 & 200 \\
2. & Gujarat & 100 & 100 & 200 \\
4. & Rawalpindi & 100 & 100 & 200 \\
& Total & 300 & 300 & 600 \\
\hline
\end{tabular}

In order to measure variables of intrinsic motivation a questionnaires was selected. Elliot and Church (1997) developed the intrinsic motivation questionnaire. The questionnaire contains items on two dimensions. The intrinsic motivation questionnaire contains items about intrinsic and extrinsic motivation. The questionnaire consisted of 30 items each, item containing two statements, one expressing intrinsic motivation and the other extrinsic motivation, each to be responded on 4 point rating scale i.e. really true for me and Sort of true for me. Intrinsic motivation was measured by item no. 1, 3, 5-6, 8-9, 12 $13,16,18,21,24,26-27$ and 29, whereas Extrinsic motivation was measured by item no.2, 4, 7, 10-11, 14$15,17,19-20,22-23,25,28$ and 30. Thus, 15 items pertained to intrinsic motivation and 15 items to extrinsic motivation. The variable of academic achievement was measured by obtaining marks of the selected students from their university results held in December. Students were asked to fill out academic scores box given in the questionnaire. They were asked to write their obtained marks out of the total marks that were not verified from their respective colleges. The marks were then converted into percentage to give them uniformity. It had also been noticed that student's achievement scores might have flaw in it as it was given by students themselves and was not verified from the college 
administration. Data were collected through questionnaires. The researcher herself visited most of the colleges and administered questions personally.

The following procedure was used to for the scoring of data on all the questionnaires:

1. The responses on intrinsic motivation questionnaire were scored by using the following scoring criteria:-

\section{Scoring procedure for extrinsic motivation}

Really, true for me

1 mark

Sort of true for me

2 marks

Scoring procedure for intrinsic motivation

Really, true for me

4 marks

Sort of true for me

3 marks

2. Academic achievement was already in the form of student's scores that were converted into percentage in order to make them uniform.

3. The scores on each variable for the research participants were calculated by summing up their scores on all the items of questionnaire. Thus, each participant had intrinsic motivation scores and academic achievement scores. These ungrouped scores were then organized into frequency distribution

Professionals in the area of psychology and education observed the validity. A sample of 150 students was taken for this purpose. The reliability of the students was then calculated by applying Cronbach's Alpha is 0.76.The nature of the study was descriptive. Data were collected through questionnaires survey from the universities of Punjab by visiting them personally. Scores were averaged out by computing the mean of the scores on each variable of intrinsic motivation and academic achievement. The data was analyzed by calculating standard deviation. In order to compare male and female on motivational variable and academic achievement t-test (two tailed) was used. The relationship on each aspect of student's motivation with academic achievement scores was calculated through product moment correlation coefficient. The level of significance used was 0.05 .

\section{Results and Discussion}

Table 1: Frequency distribution of intrinsic motivation scores of students

\begin{tabular}{ll}
\hline Class intervals & Frequencies \\
\hline $65-70$ & 3 \\
$70-75$ & 127 \\
$75-80$ & 370 \\
$80-85$ & 99 \\
$85-90$ & 1 \\
Total & 600 \\
\hline
\end{tabular}

Table 1 shows frequencies of intrinsic motivation scores. These scores were distributed in frequencies based on each student's marks on the intrinsic motivation questionnaire. The distribution of scores is normal because the frequencies are increasing up to the class interval 75-80 which has 370 students, thus falling gradually. The raw intrinsic motivation scores are given in appendix I and II. The frequency distribution of scores is graphically represented in the figure 1

Figure 1: Curve showing frequency distribution of intrinsic motivation scores

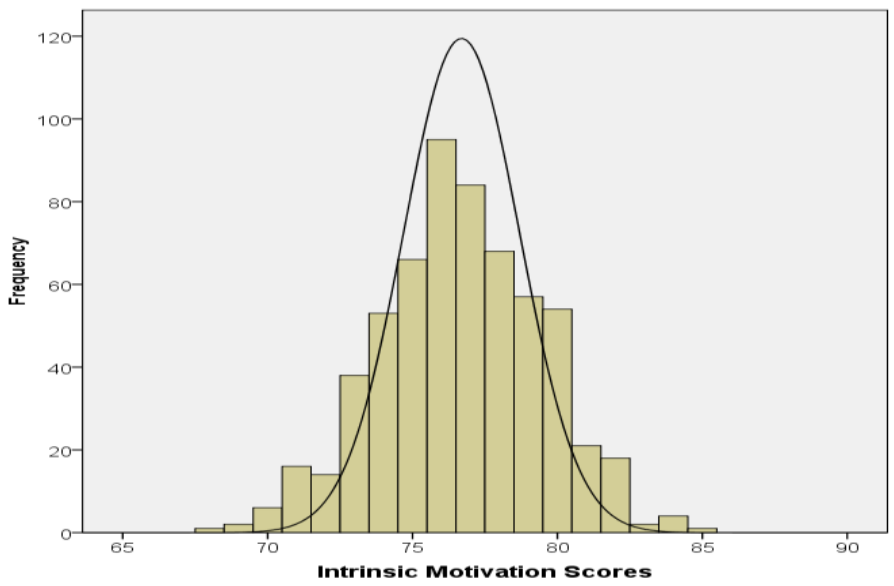


Table 2: Frequency distribution of academic achievement scores

\begin{tabular}{ll}
\hline Class Intervals & Frequencies \\
\hline $30-40$ & 121 \\
$40-50$ & 179 \\
$50-60$ & 177 \\
$60-70$ & 112 \\
$70-80$ & 11 \\
Total & 600 \\
\hline
\end{tabular}

Table 2 shows frequencies of academic achievement scores. These scores are distributed in frequencies based on each student's marks in the intrinsic motivation questionnaire. The distribution of scores is normal because the frequencies increase up to the class interval 40-50 which has 179 students, 50-60 class intervals has 177 students, 60-70 which has 112 students and 70-80 has 11 students which fall gradually. The frequency distribution of scores is graphically represented in the figure 2 .

Figure 2: Curve showing frequency distribution of academic achievement scores

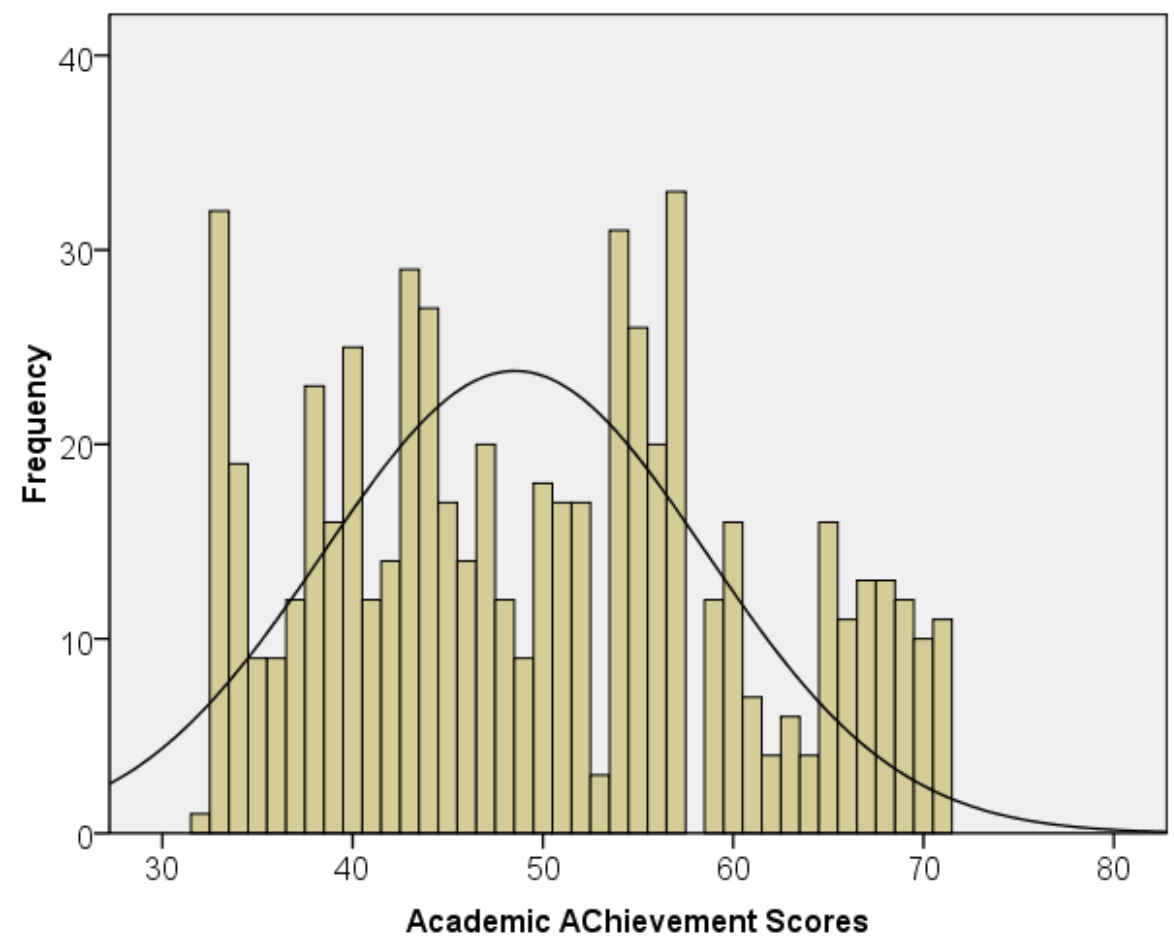

Table 3: Significance of difference between mean intrinsic motivation scores of male and female students

\begin{tabular}{|c|c|c|c|c|c|c|}
\hline Gender & $\mathbf{N}$ & Mean & SD & $S E_{\text {diff }}$ & $\mathbf{t}$ & $\mathbf{p}$ \\
\hline Male & 300 & 76.43 & 2.7 & \multirow{2}{*}{.23} & \multirow{2}{*}{.04} & \multirow{2}{*}{$\geq .05$} \\
\hline Female & 300 & 76.89 & 2.8 & & & \\
\hline
\end{tabular}

$\mathrm{df}=598$ t-value at 0.05 level $=1.96$

Table 3, the mean intrinsic motivation score of male students is 76.43 and mean of female students is 76.89 , being almost equal. The difference between mean scores of male and female on intrinsic motivation is statistically non-significant. Since t-value is less at 0.05 levels therefore, male and female students did not differ in intrinsic motivation, both groups being moderately motivated. The null hypothesis No.1 is retained. The study results revealed that both male and female students were found to be equally intrinsically motivated. The results go in line with previous researches like Hagborg (1995) Rusillo and Arias (2004). However, Ahmed and Bashir (2009) in a paper conclude female as more intrinsically motivated than males. 


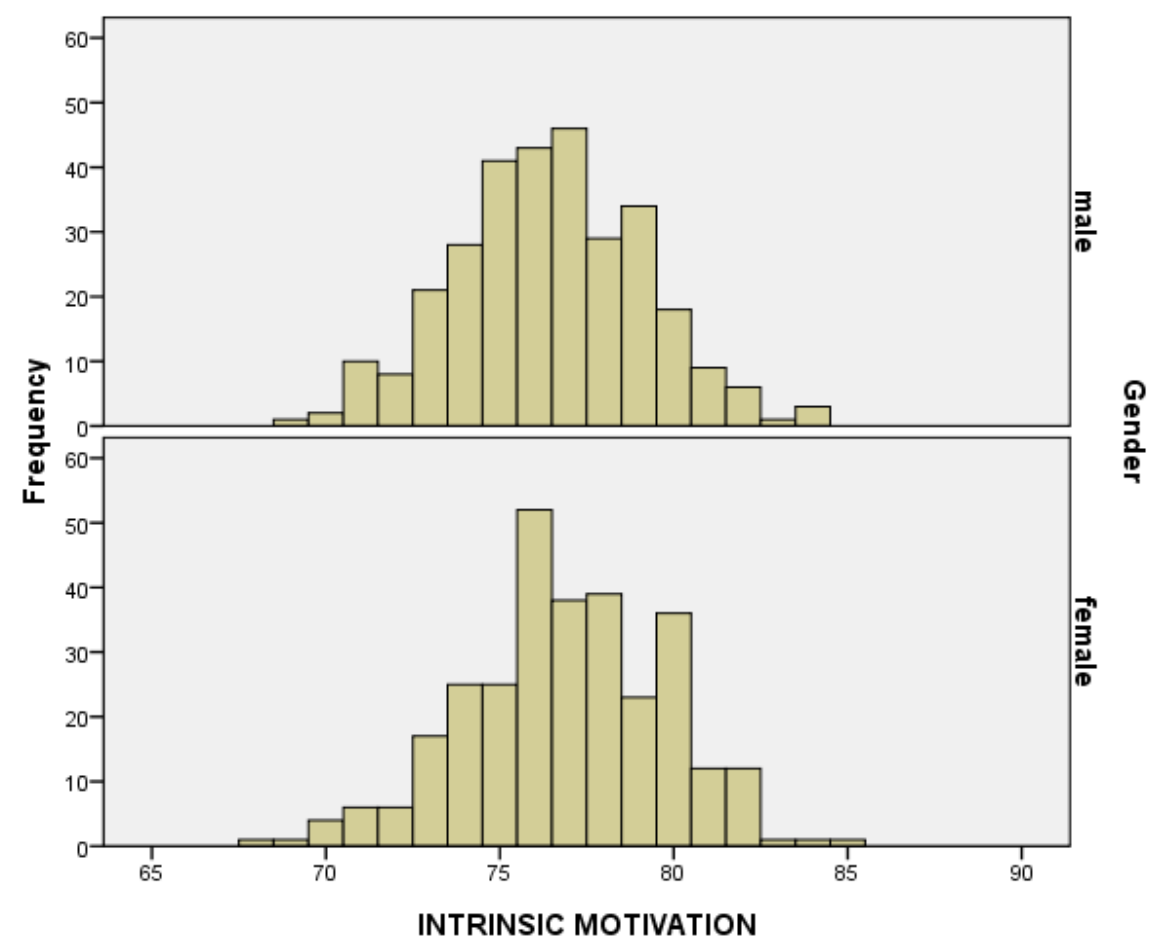

Table 4: Significance of difference between mean academic achievement scores of male and female students.

\begin{tabular}{lllllll}
\hline Gender & $\mathbf{N}$ & Mean & SD & SE $_{\text {diff }}$ & t & $\mathbf{p}$ \\
\hline Male & 300 & 49.84 & 10.83 & \multirow{2}{*}{.88} & 0.96 & \multirow{2}{*}{$\geq .05$} \\
Female & 300 & 49.89 & 10.82 & & & \\
\hline
\end{tabular}

$\mathrm{d}_{\mathrm{f}}=598 \quad \mathrm{t}$-value at 0.05 level $=1.96$

In table 4, it is shown that the mean academic achievement score of male students is 49.84 and the mean of female students is 49.89 , being almost equal. The difference between mean academic achievement scores of male and female students is non-significant. Therefore, there is no difference between academic achievement scores of both genders. The null hypotheses No. 2 is retained. The outcome of the study, that intrinsic motivation and academic achievement are positively linked with each other maintains researcher's expectations. In particular, a significant relationship between intrinsic motivation and academic achievement does exist. When intrinsic motivation increased, academic achievement also increased. It has been disclosed by the research in the area of intrinsic motivation that exterior incentives reduce intrinsic motivation (Kassin and Lepper, 1984).

Table 5: Significance of correlation between intrinsic motivation scores and academic achievement scores

\begin{tabular}{lll}
\hline $\mathbf{N}$ & $\mathbf{r}$ & $\mathbf{p}$ \\
\hline 600 & 0.59 & $\leq 0.05$ \\
\hline
\end{tabular}

$\mathrm{d}_{\mathrm{f}}=598$ ' $\mathrm{r}$ ' at 0.05 level $=0.19$

As shown in table 5, the correlation coefficient between intrinsic motivation and academic achievement scores is .59, which is greater than table value at 0.05 level and is considered as significant. Therefore, the null hypothesis No.3 is rejected. Some studies exposed by review of literature that look at motivation and academic achievement in learners. The results of this research do not hold the earlier studies carried out that show a negative association among intrinsic motivation and academic achievement (Goldberg and Correll, 1998; Stipek and Rayan, 1997). 


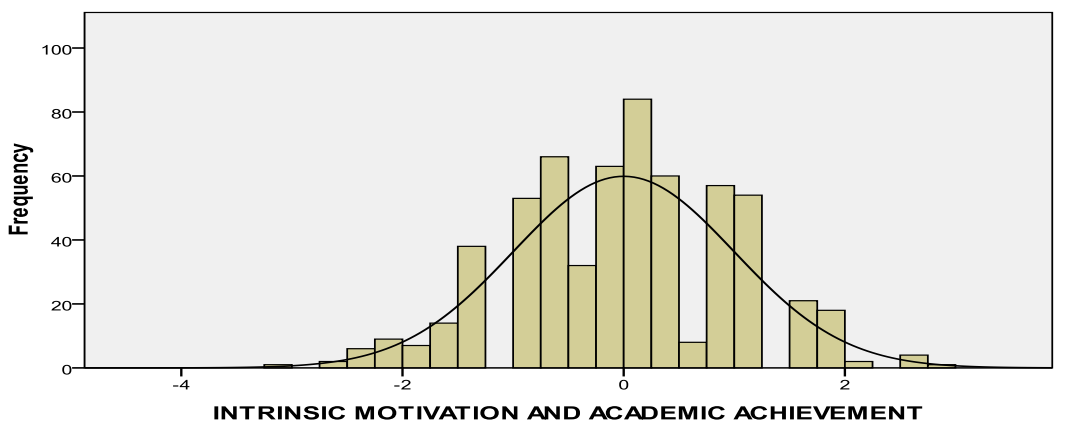

\section{Conclusion and Recommendations}

The students of bachelor degree classes of province of Punjab (Pakistan) perceived themselves to be more intrinsically than extrinsically motivated $(\mathrm{t}=.04)$. However, their average academic achievement in the college examination result was below $50 \%$. No gender differences in arts and science students could be found on the study variables. Moderate relationship was found between their perceived intrinsic motivation and actual academic achievement $(r=0.59)$. Students of higher education may be encouraged to improve their intrinsic motivation for learning just for the sake of learning. They should be given learning tasks, which are interesting to learn and indicate their engagement in learning activities. Teachers can play a crucial role in this regard who should try to find ways to involve male and female students in activities in which they consider interested and desire to accomplish. The rewards and incentives should be generally avoided because this lessons their intrinsic motivation and leads towards extrinsic motivation.

Frequent, immediate and positive feedback is given by the teacher that helps learners' ideas that they can perform better. In order to make certain chances for students' achievement and to support learners discover individual sense and importance in the subject matter educator must allocate activities to learners that are neither very simple nor very hard. They should assist learners think that they are respected individuals of a cultured society and create an atmosphere that is open and relaxed. Examination system in Pakistan is mostly traditional that encourages extrinsic motivation, performance goal orientation and use of surface study strategies. Testing method be practice that encourage student centered discovery learning more than teacher centered, direct instruction strategies.

\section{References}

Ahmed, I. \& Bashir, A. (2009). Achievement Goals Theory: Evidence from College Students in Pakistan. Pakistan Journal of Psychological Research. Government College University, Lahore. P.5.

Arif, M. H. (2003). Human Development and Learning. Majeed Book Depot, Lahore, Pakistan. 163.

Boggiano, A. A. K. S. \& Gallo, L. S. (1991). Predicting Emotional Concomitants of Learned Helplessness: the role of motivational orientation. Sex roles, 25, 577-593.

Boggiano, A. A., Barrett, K. S., Kllam, M., Thompson, T., Simons, E. J. \& Katz, P. (1992). Helplessness Deficits in Students: The Role of Motivational Orientation. Motivation and Emotion, 16, 271-296.

Elliot, E. S. \& Church, M. A. (1997). A Hierarchal Model of Approach and Avoidance Achievement Motivation. Journal of Personality and Social Psychology, 72, 218-232.

Goldberg, M. D. \& Cornell, D. G. (1998). The Influence of Intrinsic Motivation and Self Concept in Academic Achievement in Second- and Third-Grade Students. Journal of the Education of the Gifted, 3, 179205.

Harackiewicz, J. M., Barron, E. K., Elliot, J. A., Carter, M. S. \& Lehto, A. (1997). Predictors and consequences of achievement goals in the college classroom: Maintaining interest in making the grade. Journal of Personality and Social Psychology, 73, 1284-1295.

Hagborg, W. J. (1995).Gender and Motivational Orientation among High School Students. Education Resources Information Center, ED415225, 316-330. 
Harter, S. (1981). A New Self-Report Scale of Intrinsic Versus Extrinsic Orientation in the Classroom: Motivational and Informational Components. Developmental Psychology, 17, 300-312.

Hidi, S. \& Harackiewicz, J. M. (2000). Motivating the Academically Unmotivated: A Critical Issue for the 21st Century. Review of Educational Research, 70, 151-179.

Hunt, j. M. (1965). Intrinsic Motivation and Its Role In Psychological Development in D. Levine (ed.), Nebraska Symposium on Motivation. Lincoln: University of Nebraska Press, 13(22), 51-61.

Kassin, S. M. \& Lepper, M. R. (1984). Over Sufficient and Insufficient Justification Effects: Cognitive and Behavioral Development. In J. Nicholls (Ed.), the Development of Achievement Motivation. Greenwich, CT: JAI Press, 73.

Krapp, A., Hidi, S. \& Renninger, K. A. (1992). Interest, learning and development. In K.A. Renninger \& A. Krapp (Eds), the role of Interest in Learning and Development. Hillsdale, New Jersey: Lawren, 325.

Meece, L. J. \& Jones, M. G. (1996). Gender Differences in Motivation and Strategy Use in Science: are Girls Role Learners? Journal of Research in Science Teaching, 3, 393-406.

Ormroid, J. E. (1998). Educational Psychology. New Jersey: Merrill, 79.

Ryan, R. M. \& Deci, E. L. (2000). Intrinsic and Extrinsic Motivation: Classic Definitions and New Directions. Contemporary Educational Psychology, 25, 54-67.

Rusillo, M. T. C. \& Arias, P. F.C. (2004). Gender Differences in Academic Motivation of Secondary School Students. Electronic Journal of Research in Educational Psychology, 5, 97-112.

Stipek, D. \& Ryan, R. (1997). Economically Disadvantaged Preschoolers: Ready to Learn but Further to Go. Developmental Psychology, 2, 711-723.

The university of the Punjab (2011). Retrieved from www.pu.edu.gov on Nov 27, 2011.

White, R. (1959). Motivation Reconsidered The Concept of Competence. Psychological review, 66, 297333. 